\title{
The Influence Of Staff Perception Toward The Director Leadership Style, Effective Communication, Delegation And Empowerment To Form The Learning Organization And Transformation At Imelda Pekerja Indonesia Hospital
}

\author{
Imelda L.Ritonga ${ }^{1}$, Zainuddin ${ }^{2}$, Dian Armanto ${ }^{3}$ \\ ${ }^{1}$ Imelda Highest School of Health Science, Jl. Bilal Ujung No.24,52, Kota Medan, Sumatera Utara 20239, \\ Indonesia \\ ${ }^{23}$ Medan State University, Jl. William Iskandar Ps. V, Kabupaten Deli Serdang, Sumatera Utara 20222, \\ Indonesia
}

\begin{abstract}
The aims of the study is to investigate the influence of staff perception to the director leadership style, effective communication, delegation and empowerment to form the learning organization and transformation at Imelda Pekerja Indonesia Hospital in Medan, Indonesia, According to the study paradigm, the data analyzed with descriptive, correlation, regression and path analyses showed that hypotheses from the study can be accepted, and this research proved that the staff perception of the director leadership had positively influenced to the effective communication, delegation, and empowerment, and also the study paradigm suggested in this study is recommended to be a model in organization transformation based on learning organization theory. The unique of learning organization transformation model is the organization always in learning cycle to switch the organization according to the stakeholder needs. This study also recommended the significant role of the leader as inspired, counselor, and supervisor to the organization members.
\end{abstract}

Keyword: Learning Organization, Organization Transformation, Transformational Leadership, Transactional Leadership

\section{INTRODUCTION}

Transformation is the highest form of the change process. Transformation means the changes of concepts and values in the organization and not only the change of certain process or procedure. Transformation is the organization's strategy in fulfilling the challenge and demands from the outside to keep the existence and win the competition. Transformation put the organization aware of the visible changes and prepare the readiness of structure, system, process and human resources to the changes. According to Kotter[1], the change process is not easy and more likely to be failed. The reason of the failing is people resistance to the modification. The resistance is related to people failed in identified the urgency need of the change. People will resist changed when they do not have any credit from the change. An organization without transformation will be left behind and lost the competition because of less ability to fulfill the stakeholder expectation. Hospitals in Indonesia also have to internalize the new paradigm in service [2]. The new paradigm in the healthcare organization is a new focus on the quality and patient safety. The focus pushed the changes to the old values and systems. The hospital needs to apply new concepts. The health worker needs switching their beliefs. The hospital organization should do the transformation. The demands come from the government, the hospital board and public. It comes with hospital accreditation. The hospital needs to learn how to run service with a new focus, accredited by the hospital board to approve or renew the operational certification. Besides, people also demanded good service. Hospitals' competition comes from local or international companies. The more hospital can fulfill the customers' needs, the more competitive it will be. In the other hand, the hospital with low standard and lack concern for patient safety will be the source to the lawsuit.

Previous researchers found many models in transformation. All the models agree that transformation is a process. It will happen when the organization's elements support the changes. The most important factor in transformation is the human resources. Only if more people support the changes, the transformation will happen. So, people are the key to the transformation. Moreover, the most important element who can change the people mind is the leader. The most transformation will begin with the leader initiation. The leader is the inspirer, counselor, and supervisor to the organization members. The leader keeps the commitment to the transformation. The transformation is not easy because changes always make uncertainty, hesitation, and skepticism. If the leader loses the commitment, nobody will remember the process. Put the right strategy will help the leader keep the commitment. 
Peter Senge[3] introduced learning organization theory as a strategy to change the people values. According to this theory, by learning people will have more information about the good and bad things from their action and choices. Their cognitive will analyze the best for them and put the concept they accept as the based on all their action. This theory used learning adaptive cycle as the design. According to this cycle, the leader can learn the root of the problem or solve the problem by learning from the past experiences, previous researchers, or best practice. A leader will understand the phenomena of the problem if he/she found the values used by the people which become the resources of the problem. The leader can use right strategies have been improved from research or best practice to resolve the problem. The learning cycle is continuing the process to find and resolve the problem. With this cycle, the leader always could aware of the problem and find the best strategy to resolve it. In their book, Senge, Kleiner, Roberts, Ross, Roth \& Smith $\left.{ }^{[4}\right]$ talked about many strategies to sustaining momentum in a learning organization. According to the book, leader moves the change through the daily process and people should be involved and actively understand the urgency need of the change. The more people involved, the more likely change can happen. The more people involved, the leader should be able to communicate and decentralized the responsibility with the right people and structure. Beside, the leader also should supervise the ability of the members in doing their job, find the obstacles, encourage cooperation, giving feedback and stimulate critical thinking. Bass ${ }^{5}$ found that leadership style that suitable to support learning organization is transformational and transactional leadership. Those styles make the leader become inspired, counselor, and supervisor to the organization vision.

Previous researchers about change and transformation and the new paradigm in hospital services made interest to the researcher to do a study about the influence of staff perception toward the director leadership, effective communication, delegation, and empowerment to form the learning organization and transformation at Imelda Pekerja Indonesia Hospital. This study will find how to use learning organization as a strategy toward leadership, effective communication, delegation, and empowerment to support organization transformation. In this study, a researcher wants to prove that leadership style, effective communication and delegation/empowerment will influence the organization to be learning organization and make transformation happen. At the end of this study, researcher proposed the conversion model based on learning organization theory.

\section{LITERATURE REVIEW}

\section{Organization Transformation}

Many scientists have proposed the meaning of transformation. Bleak \& Fulmer [6] said that organization transformation is a strategy in business development. Furthermore, Aspara, Lamberg, Laukia \& Tikkane [7] said that transformation is the change of organization characteristic to improve the competition ability. So, a transformation is mandatory to keep the organization retains in the market. Most scientists agreed that transformation is a process. It will be started when the need of change realized by the leader or organization member. When the organization started the change, they need to formulate the vision to accomplish. All the models in transformation talked about organization elements that involved to the organization change process. The Transformational Report [8] found some transformation model which locate some organization elements. Some of them are $7 \mathrm{~S}$ from Mc.Kinsey Model with structure, system, style, staff, skills, strategy, and shared values; DR Peter Fuda with an arena, actual state, aspiration, assumption, and alignment; Schneider \& Betty, with business strategy, organization culture, and structure. According to the models, all the elements related one another, work together to reach one goal/vision. So, the transformation will start when the organization aware the need of change, have one vision to accomplish, and able to work together to achieve the vision.

Unfortunately, a transformation is hard because of the people resistance. People resist changing because cognitively they cannot analyze their profit from the change. Slocum \& Hellriegel [9] said that individual behaviors are created based on their beliefs. The beliefs are formed by human personality, learning desire and motivation. Furthermore, human personality formed by self-esteem, a locus of control, and emotional intelligence. According to Sujanto, Lubis \& Hadi [10], human personality is relatively permanent, but it is still can be changed. Peter Kline in Kotter[1] said people resisted to change but according to Senge, et.al.[4] people are permeable to receive information and can understand the external changing. All the information will analyze by the human cognitive and compared to their memory. If the information analyzed as something good and needed by them, they will accept the information as positive, but if they analyze as something useless, painful, burdening, they will accept the information as negative. However, as mentioned above, human personality will function as a filter to the information. According to this theory, people in an organization are the flock of the human with a different personality. So, the same information will accept individually. However, there is always a chance and opportunity to make people accept the change because of the ability of human cognitive to analyze.

Senge, et.al[4] bring up a strategy to help people in organization accept change. They introduce about learning organization. Learning organization is a strategy used to understand the lack/obstacle in organization 
elements that become the source of the problem. By learning the problem, the leader will be able to sort the problem and push the people to engage in the problem resolve. Transformation model according to learning organization has specific strategy. It more focuses to invite individuals involved in the transformation agenda by provided information and divided responsibility widely to the organization members. The learning organization theory believes people will involve if they emerged their need to the changes. Further, the need will emerge if the people grow the feeling like part of the organization.

\section{A. Learning Organization}

Peter Senge [3] said that learning organization is an organization that continuing to improve in created the better future. According to Wang [11], the differences between learning organization and traditional organization are the attitude to change. The learning organization always open to the change, eager to learn new ideas, innovation, learn to adapt and find knowledge, skill or ability to increase competition, and share the responsibility to defend the organization. In the learning organization, everybody encouraged to understand the future of the organization, strategy, and skills needed to fulfill the future.Learning organization has five disciplines to be internalized by the organization members, they are (1) system thinking, (2) mental model, (3) team learning, (4) shared vision, (5) personal mastery. The fifth disciplines are the principles how people should behave in the learning organization. System thinking is the process of working. All the work should follow a certain system. A mental model is the capacity people used to judge or make the value in work. Team learning is the commitment to share the responsibility for resolving the problem and improve the work. A shared vision is the commitment to achieve one goal. Personal mastery is the commitment from the organization members to master the skill, knowledge, and ability to do their responsibility, in a learning organization, change is promoted by the adaptive learning cycle. The adaptive learning cycle stimulates the critical, thinking of the organization members to learn the problem, modified the question, evaluate and continue observing the improvement and identified new improvement. The Adaptive Learning Cycle from Senge, et.al.[4] shown bellow:

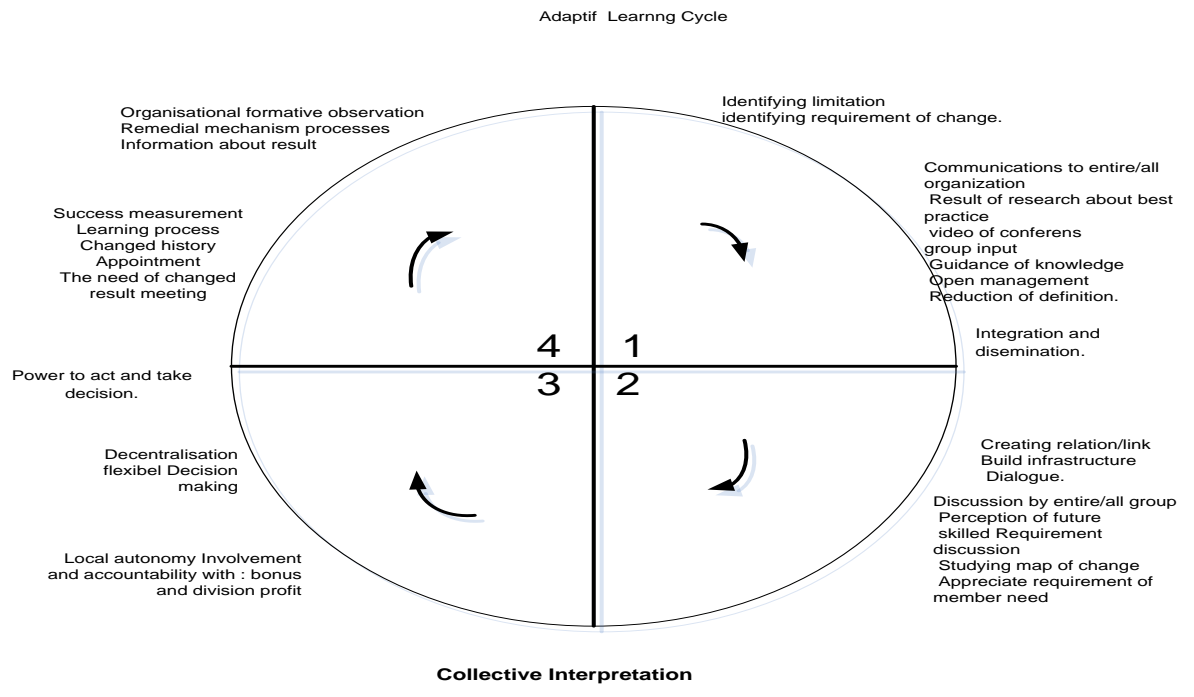

Fig 1. The Adaptive Learning Cycle

As shown by the cycle, the characteristic of the learning organization is always looking for improvement by continued identified the need of change to fulfill the stakeholder's demand or increase the competitiveness. Learning organization always encourage teamwork, system approach, and engage as much as people involved. To push the involvement of people in the transformation agenda, Gil, Rico, Alcover \& Barasa[12] said about team climate. Team climate is the condition created by the acceptance of the values and system in the group. The harmony in the group will be formed if more people accepted the values as personal values. According to Gil, et.al.[12], people will accept the values if they have felt like part of the group, less suspicion one another and accept by the group. The harmony promotes conducive situation and increases the interaction between the members. To improve the harmony, a leader can use real management and divide the delegation and empowerment fairly. Conducive situation will improve learning in the organization because the condition will strengthen the communication and learning process

\section{B. Leadership Style}

Leadership style is the leader attitude, behavior, communication and courage in making decision, and innovation to achieve the organization vision. According to Kontoghiorghes, et.al.[13] the leadership style that 
promoted change in an organization encourages open communication, and information dissemination, innovation, and risk were taken, and professionalism. Higgs \& Rowland [14] said that leader is a sharper to the right values and organization's policies. The leader should educate the organization members to do the right things according to the right values and policies. The leader is also a model for the organization's values, so the organization's members can observe the values requirement in the leaders' act. Karp \& Helgo[15] said that people would change if they have been informed about the organization's objectives, right values and also found the model of the values from the leader.

According to Bass [5], the leadership style that supports learning organization is transformational and transactional leadership. Bass \& Avolio[16] noted four dimensions of transformational leadership which are (1) idealism influence, (2) inspirational motivation, (3) intellectual stimulation, (4) attention. In idealism influence, the leader encourages the involvement of organization members with appreciated the members' ability and respect their existence. In inspirational motivation, leader helped the members to find the meaning of their job. In intellectual stimulation, the leader encourages the individual ability to analyze the cause of the problem and find how to make the system better. So in individual consideration leader encourage the members' involvement by putting concern for their needs, attitude, and behavior individually. Dvir, Eden, Avolio \& Shamir[17] found that transformational leadership showed a positive relationship with building teamwork and work performance. They also found that transformational leadership increase organization commitment such as members' loyalty, and willingness to hard work. The commitment also increased the job satisfaction and job performance. In the end, it also increased the member's sense of belonging and motivation to promote the organization further.

Transactional leadership is leadership with more concern in giving appraise according to work performance. The leader formed the members' attitude and behavior with reward and punishment. Bass ${ }^{7}$ said the manifestation of transformational and transactional leadership would show as (1) inspirational leader, (2) intellectual stimulation, (3) proper consideration, (4) appraise accordingly, (5) supervise, (6) proactive to identify problem and weakness.

\section{Effective Communication}

Communication is changing information process to build understanding between the communicators. The communication is effective if all the communicator's success in the construction of the right understanding. The communication can be not effective if the message become unclear or some disturber come to the process. In the learning organization, effective communication is one strategy to spread the information so the members can have the same understanding about organization vision, strategy, system, policies, and process. The more information is spreading, and the more people can be expected to involve in the change process. According to Senge,et.al.[4] in the learning organization, effective communication also put the leader in concern to the member's difficulty or obstacle and not only pushing the organization interest. Effective communication also means that the leader appreciates all the ideas come from the members.

In the learning organization, effective communication is used as a strategy to educate members about the right values and policies. The leader is the model of the values. The members can observe the congruence of the leader's action and his/her talk. This is call walk the talk. By become the model for the values, people can understand the requirement of the values and how the values can be applied. This strategy also put the people in harmony, because with the real example, people can be more certain about how the values applied.

In the learning organization, effective communication is fundamental to encourage good cooperation. Fail to make effective communication, will make the information stop or delay. Garvin[18] said that to build effective communication, a leader should able to identify the obstacle of communication, and members' attitude and behavior that become disturbed to the communication process. Gibson, Ivancevich, Donnelly \& Kanopaske[19] said that to push effective communication, people should learn how to communicate with emotional intelligent. Emotional intelligent is the ability to control and show the right attitude and behavior accordingly to strengthen the message. Beside emotional intelligent, to make the message clear, the communication should base on objective data and do not influence by a personal problem.

\section{Delegation and Empowerment}

Delegation and empowerment are the distribution of responsibility and authority in the organization. According to Mushipe [20], delegation and empowerment are strategies to design the decision maker, dissemination of information and accountability. By distribute responsibility and power, people will feel appreciate and encourage to involve in organization interest. The leader ability to understand the competence, attitude, and behavior from the members individually is required to make proper delegation and empowerment system. Right position will encourage people to work harder because their confidence to the job and responsibility given. The more people feel comfortable with their job, the more they are involved in organization interest. 
Learning organization has a specific system in the distribution of responsibility and authority. The distribution used flat structure means a shorter link between high level and bellow. This kind of distribution will encourage closer and faster communication, and emphasize quicker settlement. The characteristic of a learning organization is encouraged more connectivity. Fast information exchange is necessary. Delay is avoided. So, by using the shorter link, interconnection will be easier. A shorter link means responsibility and authority are distributed until lower level. Moreover, lines of communication are open at the highest level. To enlarge the communication lines, a leader could open informal beside the formal communication. The learning organization put everybody informally on the same level to avoid hesitancy to communicate.

In the learning organization, a leader has a responsibility to guide the members' perceptive in doing their job. Daft[21] said the objective in doing supervision is to ensure everybody understands how to do their work rightly. By doing supervision, leader immediately finds the potential cause of failure or problem before become bigger. Furthermore, supervision is also a strategy to improve the quality of organization outcome.

\section{E. Research Paradigm}

Based on the literature review, this study proposed research paradigm as bellow:

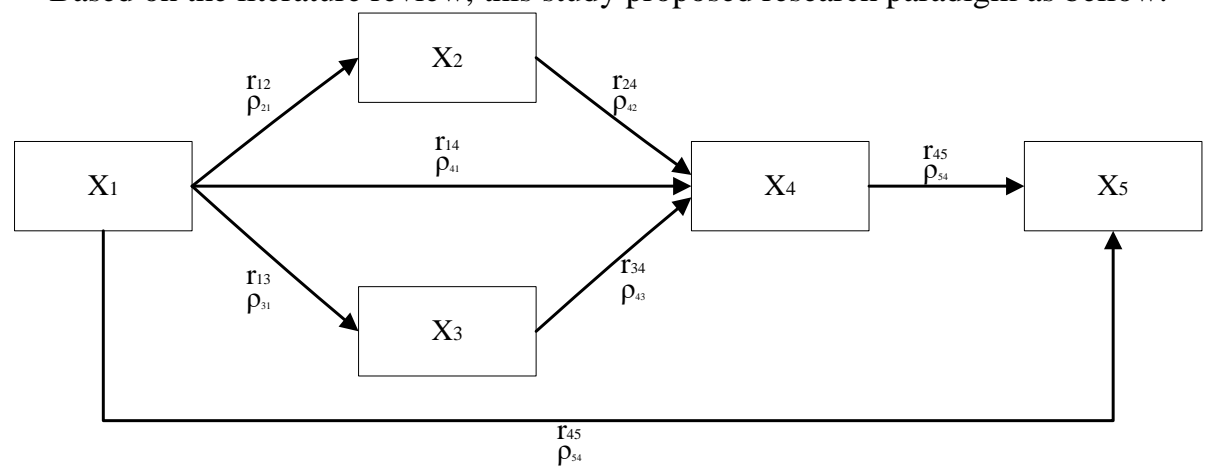

Fig 2. Research Diagram

Description:

$\mathrm{X}_{1}$ : Leadership style

$\mathrm{X}_{2}$ : Effective communication

$\mathrm{X}_{3}$ : Delegation/empowerment

$\mathrm{X}_{4}$ : Learning organization

$\mathrm{X}_{5}$ : Organization transformation

Hypothesis

The hypothesis formulation in this study is:

(1) Individual perceptions of leadership style influenced organization transformation;

(2) Individual perceptions of learning organization influenced organization transformation;

(3) Individual perception of leadership style influenced learning organization;

(4) Individual perception of leadership style influenced effective communication;

(5) Individual perception of leadership style influenced delegation/empowerment system;

(6) Individual perception of effective communication influenced learning organization;

(7) Individual perception to delegation/empowerment system influenced learning organization.

\section{PROPOSED METHOD}

The methodology used in this research was surveyed with causal technique and path analysis used to analyze the impact of variables. Data was collected with a questionnaire. The questionnaire constructed based on an academic review, debriefing with a few hospital leader, and discussion with the promoter. Likert Scale was used for the responses. Before use, validation and reliability test were sought. The population in this research was a permanent employee in Imelda Pekerja Hospital. The sample was taken according to purposive sampling. The sample included in this research was doctors, nurses, midwifery, radiographer, laboratories, dietician, pharmacist, health promoter, medical record, and administrator. The sample was considered as the most appropriate to provide data. The total population was arranged based on the functional unit. The grouping was more appropriate to investigate connectivity, collaboration, communication and delegation/authority distribution which are expected in learning organization theory. Total population in each unit was identified, and a sample was taken from each unit using proportional random sampling. The total population was 364 , and total sample was 191 . 
Requirement test to the data sought before data was used to analyze hypothesis. According to the hypothesis and research paradigm, data was analyzed with correlation, simple regression and multiple regressions using SPSS 17. From the analysis, the relationship and impact between variables by research paradigm confirmed.

According to the research paradigm and the hypothesis, the paradigm can be divided in four sub structure, there were:

1. Sub structure I:

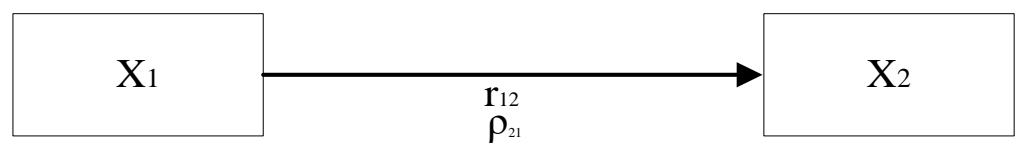

Fig 3. Sub Structure 1

$\mathrm{r}_{12}=\rho_{21}$

2. Sub structure II:

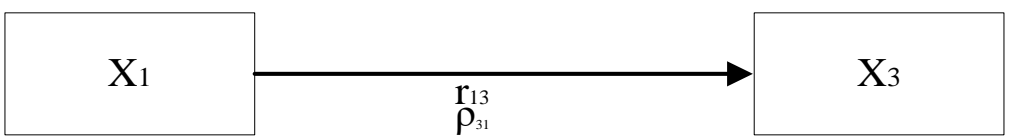

Fig 4. Sub Structure 2

$\mathrm{r}_{13}=\rho_{31}$

3. Sub structure III:

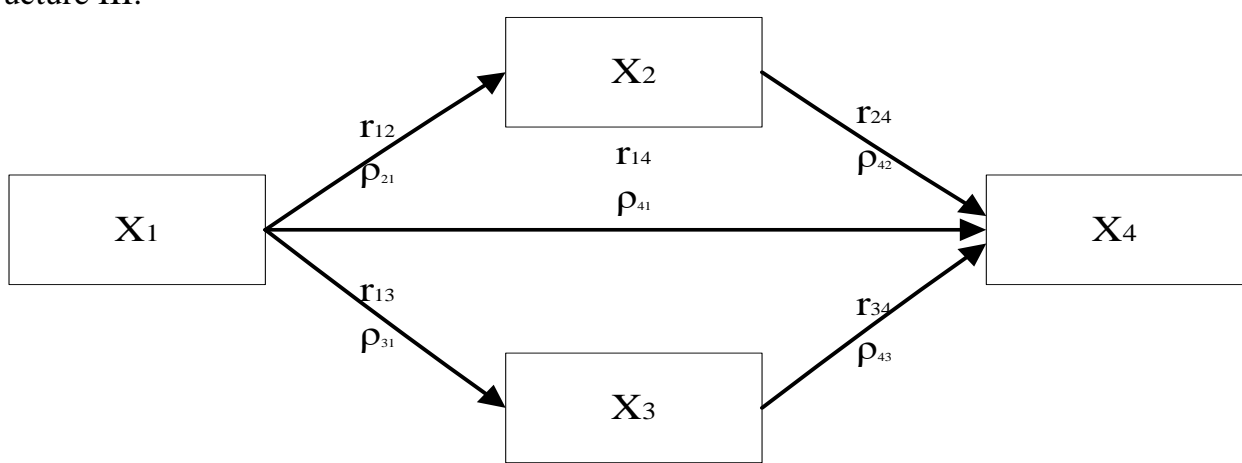

Fig 5. Sub Structure 3

$$
\begin{aligned}
& r_{14}=\rho_{41}+\rho_{42 .} r_{24}+\rho_{43} r_{34} \\
& r_{24}=\rho_{42}+\rho_{41} r_{14}+\rho_{43} r_{34} \\
& r_{34}=\rho_{43}+\rho_{42 .} r_{24}+\rho_{41} r_{14}
\end{aligned}
$$

4. Sub structure IV:

5 .

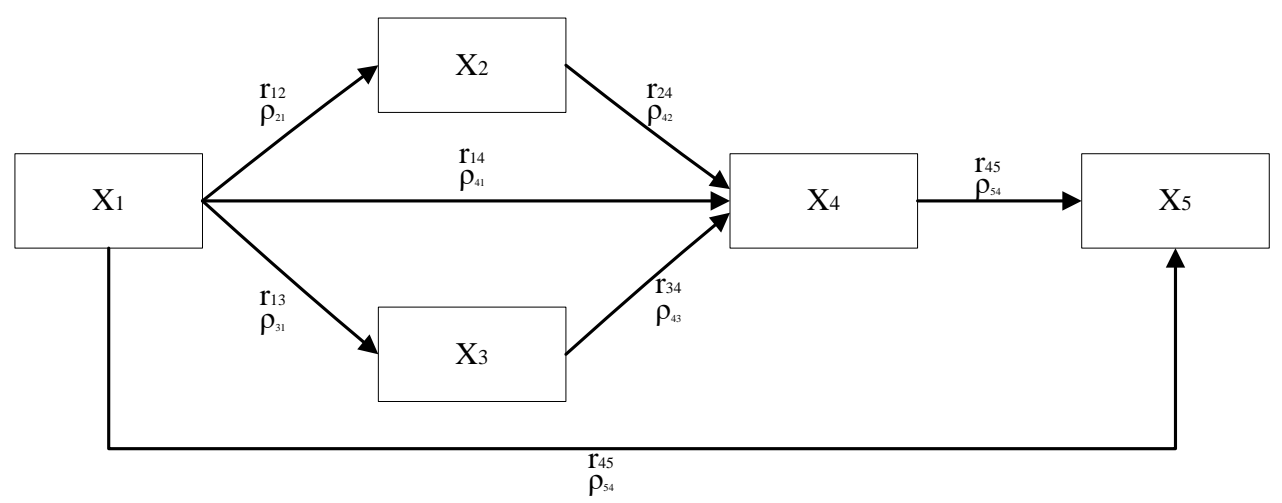

Fig 6. Sub Structure IV

Note :

$$
\begin{aligned}
& r_{15}=\rho_{51}+\rho_{54} r_{45} \\
& r_{45}=\rho_{54}+\rho_{51} r_{15}
\end{aligned}
$$

$r=$ Correlation coefficient 
$\rho=$ Path coefficient

\section{RESULT AND DISCUSSION}

Requirement test done were normality and linearity with the significance of regression. KolmogorovSmirnov was used for normality test, test for linearity was used for linearity, and simple regression was used to find the coefficient of regression. All variables found normal and linear with coefficient regression confirmed a significant relationship between variables.

Descriptive analysis showed the middle tendency in all variables. The finding encouraged possibility improvement in all variables. The study finding can be used as strategies to make the improvement. Product Moment was used to analyses the significant correlation between variables. The finding confirmed that all variables were significantly had a positive correlation. Furthermore, simple regression analyses confirmed that all independent variables were significantly had an impact on the dependent variables.

The hypothesis was analyses with path analyses according to the research paradigm. The hypothesis was confirmed according to the path coefficient, $t$ value and significant as bellow:

1. Sub Structure 1:

Hypothesis 4 : Individual perception to leadership style influenced effective communication;

$\rho_{21}=0,734 ;$ t-value $=14,850 ;$-value $=0,050$ ( t-value $>$ t-table $; \mathrm{p}$-value $\left.>0,050\right)$ : confirmed.

2. Sub Structure 2:

Hypothesis 5 : Individual perception to leadership style influenced delegation/empowerment; $\rho_{31}=0,543 ; \mathrm{t}$-value $=8,889 ; \mathrm{p}$-value $=0,050(\mathrm{t}$-value $>\mathrm{t}$-table $; \mathrm{p}$-value $>0,050):$ confirmed 3. Sub Structure 3:

Hypothesis 3 : Individual perception to leadership style influenced learning organization;

$\rho_{41}=0,192 ; \mathrm{t}$-value $=1,878 ; \mathrm{p}$-value $=0,031(\mathrm{t}$-value $>\mathrm{t}$-table $; \mathrm{p}$-value $>0,050):$ confirmed

Hypothesis 6 : Individual perception to leadership style influenced learning organization;

$\rho_{42}=0,219 ; \mathrm{t}$-value $=2,867 ; \mathrm{p}$-value $=0,025(\mathrm{t}$-value $>\mathrm{t}$-table $; \mathrm{p}$-value $>0,050):$ confirmed

Hypothesis 7 : Individual perception to delegation/empowerment influenced learning organization

$\rho_{43}=0,140 ;$ t-value $=1,832 ; \mathrm{p}$-value $=0,0345(\mathrm{t}$-value $>\mathrm{t}$-table $; \mathrm{p}$-value $>0,050):$ confirmed

4. Sub Structure 4:

Hypothesis 1: Individual perception to leadership style

influenced organization transformation;

$\rho_{51}=0,791 ; \mathrm{t}$-value $=18,282 ; \mathrm{p}$-value $=0,000(\mathrm{t}$-value $>\mathrm{t}$-table $; \mathrm{p}$-value $>0,050):$ confirmed

Hypothesis 2 : Individual perception to learning organization

influenced organization transformation;

$\rho_{54}=0,096 ; \mathrm{t}$-value $=2,214 ; \mathrm{p}$-value $=0,014(\mathrm{t}$-value $>\mathrm{t}$-table $; \mathrm{p}$-value $>0,050):$ confirmed

Organization transformation is something required to increase the ability to compete. Without transformation, an organization will lose the market because unable to fulfill stakeholder demands. Transformation is hard because people resistance to change. People are likely to resist the change because they do not think that the change will give them any profit. People will involve in transformation if cognitively they can analyze the need of change for the organization and them. Many transformation models have introduced. One interest theory related to people cognitive analysis is learning organization theory. According to this theory, the change process is done by the daily process. People involvement is encouraged by wide information dissemination, connectivity through communication and empowerment/delegation. Besides, based on this theory, a leader becomes an essential element to initiate and keep the transformation commitment.

This study investigated five variables which are related to the learning organization, leadership style, and organization transformation. Based on literature reviews, research paradigm had formulated. There was seven hypothesis stated. The hypothesis had examined according to statistical rules. All of the hypothesis had confirmed. In conclusion from the finding and previous research and theories, researcher proposed transformation model based on learning organization theory as bellow: 


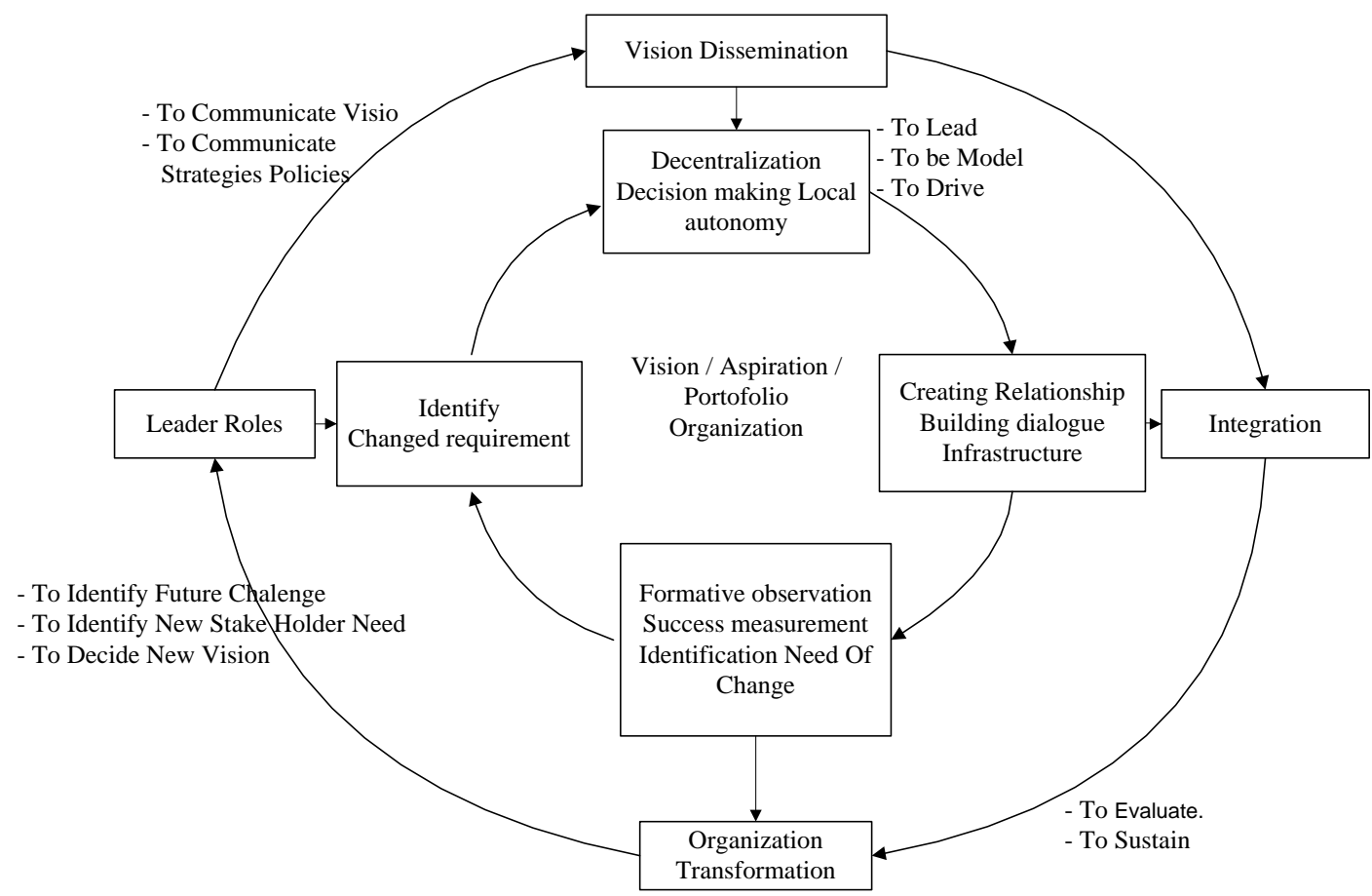

Fig 7. Learning Organization Transformation Model

Based on learning organization theory and this study finding, adaptive learning cycle can be used to encourage people to accept changes through individual cognitive analyses. The transformation will start when the leader or other organization member identified the need of change. The urgency of change is always related to organization sustainability to encounter stakeholder demands and external changing. According to a learning organization, the leader is the most appropriate to initiate the new vision/portfolio. By using adaptive learning cycle, the new concepts/values introduced. Learning organization is more emphasize of people engagement through the widely dissemination of information. To support the information dissemination, strategies recommended are effective communication and delegation/empowerment. In the learning organization, a leader is acted as inspired, consultant, and supervision. The leader has a role in guiding the organization members to understand the urgency need of change, translate the new system, supervised them to do work rightly.

According to learning organization theory, people only accept change if they analyze it as more profit for them. Based on cognitive appraisal theory, people perception is formed based on their personality, learning desires, and motivation. Moreover, personality is formed based on self-esteem, the locus of control and emotionally intelligent. Senge, et.al[4] bring up an interesting theory about how to shape people new perception through the adaptive learning cycle. The cycle is used as a strategy to spread information widely to the organization members to influence their cognitive analyses about the need of change for the organization and also for them, what changes to be made and how to apply it correctly. Learning the cause of the problem, and resolve it in a daily process is the core point in the cycle. By doing the cycle, leader and organization members identified the actual object to change, spread the new values and process, do the new way and evaluate the benefit. The cycle makes people open their new perspective and formed new perception.

Further interesting strategy in the learning organization is interconnectivity. Learning organization encourages more connection between individuals and units. Strategies to encourage the connection are effective communication and delegation/empowerment. With effective communication, people will be in the same area because they have the same message. To build true perception, people should have clear information about vision, values, policies, system and process according to the organization interest. In this study, a researcher found effective communication and delegation/empowerment influenced by leadership style. Based on transformational and transactional leadership style, in this study researcher found to encourage the change leader should formulate positive vision to achieve, communicate it, become a model, take a risk with innovation, stimulate critical thinking, promote teamwork, and coach the team with evaluation and supervision. This study confirmed that leadership style has positively influenced to promote effective communication and delegation/empowerment. Clear communication about vision, values, policies, system and process started with model showed by the leader. By the example, people perception will shape. The same acceptance will promote favorable climate, communication by objective and emotionally intelligent. Moreover, by encouraging 
teamwork, the leader will more emphasize delegation/empowerment. Leader keep does evaluation and supervision.

From a recent study, a researcher also found that in the learning organization, the transformation is continuing the process to improve an organization facing demand and challenges. Although the learning organization does believe that the responsibility of organization future is to everybody inside the organization, a leader is the most important element to see next vision to be achieved to keep organization survives and competitive. New vision or organization portfolio put the organization always aware with external changing and change properly with no delay. The researcher put transformation model based on this research finding as a cycle. The cycle showed transformation process always continues to find a new vision, spread the vision, involved people, and always do check how organization performance fulfill the stakeholder need. The model has two layers. The outside layer described how organization achieved the vision and identified new vision. Whether the inside layer described how the vision spread by leadership style, communication, and delegation/empowerment. The entrance for the process may come from the leader, people recognition of the need of change or emphasize vision from external. However, learning organization belief leader is the most important element to initiate and keep the commitment.

\section{CONCLUSION}

The organization needs a transformation to keep competitive and sustainable. However, transformation is not easy because people need to accept and involved to the transformation. Unfortunately, people will not involve if they do not have any profit to do so. Learning organization bring up strategies to shape people perception understand the profit of change and transformation for the organization and them. The theory proposed learning adaptive cycle in a daily basis to help people understand what to be changed, how and why it should be modified. This cycle will put the people exposed to extensive information about the change and the benefit from the change. The study proved that leader is the most important element to start and the commitment to vision achieved. The strategies proposed by learning organization formulated as a research paradigm in this study. Leadership style, effective communication and delegation/empowerment proved had positively influenced to build learning organization and encouraged transformation. The main point of the strategies is how to make people understand the vision, what contribution they should give, and what benefit from the transformation to them and organization. This study proved that leadership style is significantly affected all the chains forward. Based on the survey researcher is proposed learning organization transformation model. The peculiarity of this model is the continuing process to achieve a certain vision and create a new vision. This model will keep the organization sustainability.

\section{REFERENCES}

[1] Kotter, JP. Leading change: Why transformation efforts fail. USA: Harvard Business Press Books. 2011: 1-15.

[2] Schyve, PM. Leadership in healthcare organizations: A guide to joint Commission leadership standards. A governance Institute white paper. http://www.ashpfoundation.org.pdf. 2012: 1-35.

[3] Senge, PM. The fifth discipline: The art and practice of the learning organization. New York, NY: Double-day. 1990.

[4] Senge, PM, Kleiner, A, Roberts, C, Ross, R, Roth, G \& Smith, B. The dance of change: A fifth discipline resource: The challenges of sustaining momentum in learning organization. London: Nicholas brealy publi shing. 2008.

[5] Bass, BM. The future of leadership in learning organization. The Journal of leadership studies. 2000; 7(3): 18-40.

[6] Bleak, JL \& Fulmer, RM. Strategically developing strategic leaders. Best practice in leadership development handbook ( $2^{\text {nd }}$ ed). San Francisco: Pfeiffer. 2009.

[7] Aspara, J, Lamberg, J, Laukia, A \& Tikkane, H. Corporate business model transformation and interorganizational cognition: The case of Nokia. http://www/sciencedirect.com. 2014.

[8] The transformational report. www.transformationalleadership.net. 2012; 2-19

[9] Slocum, Jr JW, Hellriegel, D. Principles of organizational behavior (12 ${ }^{\text {th }}$ ed). Canada: Cengage Learning; 2009: 66-84.

[10] Sujanto, A, Lubis, H, \& Hadi, T. Psikologi kepribadian (cetakan ke-14). Jakarta: Bumi Akasara

[11] Wang, PY. Human resource management plays a new role in learning organization. The journal of human resource and adult learning. 2006: 52-56

[12] Gil, F, Rico, R, Alcover, CM \& Barrasa, A. Change-oriented leadership, satisfaction and performance in work groups: Effects of team climate and group potency. 2005; 20(3/4): 312-328. 
[13] Kontoghiorghes, C, Awbrey, S, \& Freurig, P. Examining the relationship between learning organization dimensions and change adaptation innovation as well as organizational performance. http://www2.warwick.ac.uk.pdf. 2013.

[14] Higgs, M. \& Rowland, D. Building change leadership capacity 'the quest for change competence. Journal of change management. 2000; 1(2): 116-130.

[15] Karp, T \& Helgo, T. From change management to change leadership: Embracing chaotic change in public service organization. Journal of change management. 2005; 8(1): 85-96.

[16] Bass, BM \& Avolio, BJ. The implications of transactional and transformational leadership for individual, team and organizational development. Research in organizational change and development. 1990; 4: 231272.

[17] Dvir, T, Eden, D, Avolio, BJ \& Shamir, B. Impact of transformational leadership on follower development and performance: a field experiment. Academy of Management journal. 2002; 45(4): 735744.

[18] Garvin, DA \& Robert, MA. Change through persuasion. HBR's 10 must reads on change management. USA,: Harvard business press books. 2011: 17-33.

[19] Gibson, JL, Ivancevich, JM, Donnelly, Jr, JH \& Kanopaske, R. Organizations: behavior, structure, processes (13 ${ }^{\text {th }}$ ed.). New York: McGraw-Hill. 2009: 90-96.

[20] , Mushipe, ZJ. Employee empowerment and job satisfaction: A study of the employees in the food manufacturing sector in Zimbabwe. Interdisciplinary journal of contemporary research in business. 2011; 3(8): 19-41.

[21] Daft, RL. The leadership experience ( $3^{\text {rd }}$ ed). Canada, South Western: Thomson cooperation; 640-646. 